\title{
The carbonate concentration mechanism of Pyropia yezoensis (Rhodophyta): evidence from transcriptomics and biochemical data
}

\author{
Baoyu Zhang ${ }^{1,2}$, Xiujun Xie ${ }^{1,2}$, Xuehua Liu ${ }^{1,2}$, Linwen $\mathrm{He}^{1,2}$, Yuanyuan Sun ${ }^{1,2}$ and Guangce Wang ${ }^{1,2^{*}}$
}

\begin{abstract}
Background: Pyropia yezoensis (Rhodophyta) is widely cultivated in East Asia and plays important economic, ecological and research roles. Although inorganic carbon utilization of $P$. yezoensis has been investigated from a physiological aspect, the carbon concentration mechanism (CCM) of $P$. yezoensis remains unclear. To explore the CCM of $P$. yezoensis, especially during its different life stages, we tracked changes in the transcriptome, photosynthetic efficiency and in key enzyme activities under different inorganic carbon concentrations.

Results: Photosynthetic efficiency demonstrated that sporophytes were more sensitive to low carbon (LC) than gametophytes, with increased photosynthesis rate during both life stages under high carbon $(\mathrm{HC})$ compared to normal carbon (NC) conditions. The amount of starch and number of plastoglobuli in cells corresponded with the growth reaction to different inorganic carbon (Ci) concentrations. We constructed 18 cDNA libraries from 18 samples (three biological replicates per $\mathrm{Ci}$ treatment at two life cycles stages) and sequenced these using the Illumina platform. De novo assembly generated 182,564 unigenes, including approximately 275 unigenes related to CCM. Most genes encoding internal carbonic anhydrase (CA) and bicarbonate transporters involved in the biophysical CCM pathway were induced under LC in comparison with NC, with transcript abundance of some PyCAs in gametophytes typically higher than that in sporophytes. We identified all key genes participating in the C4 pathway and showed that their RNA abundances changed with varying $\mathrm{Ci}$ conditions. High decarboxylating activity of PEPCKase and low PEPCase activity were observed in P. yezoensis. Activities of other key enzymes involved in the C4-like pathway were higher under HC than under the other two conditions. Pyruvate carboxylase (PYC) showed higher carboxylation activity than PEPC under these Ci conditions. Isocitrate lyase (ICL) showed high activity, but the activity of malate synthase (MS) was very low.

Conclusion: We elucidated the CCM of P. yezoensis from transcriptome and enzyme activity levels. All results indicated at least two types of CCM in P. yezoensis, one involving CA and an anion exchanger (transporter), and a second, C4-like pathway belonging to the PEPCK subtype. PYC may play the main carboxylation role in this C4-like pathway, which functions in both the sporophyte and gametophyte life cycles.
\end{abstract}

Keywords: Carbon concentrating mechanism, Enzyme activity, Pyropia yezoensis, Photosynthetic efficiency, Transcriptome

\footnotetext{
* Correspondence: gcwang@qdio.ac.cn

${ }^{1}$ Key Laboratory of Experimental Marine Biology, Center for Ocean Mega-Science, Institute of Oceanology, Chinese Academy of Sciences, Qingdao, China

²Laboratory for Marine Biology and Biotechnology, Qingdao National Laboratory for Marine Science and Technology, Qingdao, China
}

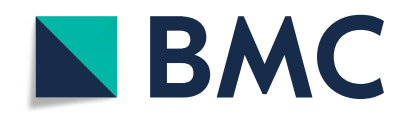

(c) The Author(s). 2020 Open Access This article is licensed under a Creative Commons Attribution 4.0 International License, which permits use, sharing, adaptation, distribution and reproduction in any medium or format, as long as you give appropriate credit to the original author(s) and the source, provide a link to the Creative Commons licence, and indicate if changes were made. The images or other third party material in this article are included in the article's Creative Commons licence, unless indicated otherwise in a credit line to the material. If material is not included in the article's Creative Commons licence and your intended use is not permitted by statutory regulation or exceeds the permitted use, you will need to obtain permission directly from the copyright holder. To view a copy of this licence, visit http://creativecommons.org/licenses/by/4.0/. The Creative Commons Public Domain Dedication waiver (http://creativecommons.org/publicdomain/zero/1.0/) applies to the data made available in this article, unless otherwise stated in a credit line to the data. 


\section{Background}

Seaweeds are important marine photoautotrophs, playing an important part in global primary production and carbon sequestration [1-3].

The carbon in seawater exists in three forms: carbonic acid $\left(\mathrm{H}_{2} \mathrm{CO}_{3}\right)$, bicarbonate ions $\left(\mathrm{HCO}_{3}{ }^{-}\right)$and carbonate ions $\left(\mathrm{CO}_{3}{ }^{2-}\right)$. Approximately $90 \%$ of the total organic carbon in seawater is present as bicarbonate ion [4]. Due to the low amount of $\mathrm{CO}_{2}$ in seawater, most macroalgae have evolved a carbon concentrating mechanism $(\mathrm{CCM})$ to utilize $\mathrm{HCO}_{3}{ }^{-}$for maintaining high levels of growth [5-7]; these CCMs are increasingly important because rising $\mathrm{CO}_{2}$ in the air has led to rising levels of $\mathrm{HCO}_{3}{ }^{-}$in water over the past few decades [8, 9]. Despite the ecological, economic and cultural importance of macroalgae, we know relatively little about their CCMs.

Various types of CCMs have been discovered in terrestrial plants and microalgae: biophysical, biochemical and basal CCM, respectively. Biophysical CCMs involve carbonic anhydrase (CA) and bicarbonate transporters (BCT). A biochemical CCM is also called the C4-like pathway. Three subtypes of $\mathrm{C} 4$ photosynthesis are recognized, based on the principal decarboxylating enzyme used in the bundle sheath: NADPmalic enzyme (NADP-ME), NAD-malic enzyme (NAD-ME) and phosphoenolpyruvate carboxykinase (PEPCK) [10]. Mitochondrial $\gamma$-CAs and $\mathrm{NADH}$-ubiquinone oxidoreductase complex I are the main components in basal CCM $[11,12]$.

Species of the genus Pyropia belong to the Rhodophyta are among the most economically important macroalgae in East Asia, including China, Japan and South Korea. The Pyropia life cycle involves a macroscopic leafy thallus phase (gametophyte) and a microscopic filamentous thallus phase (sporophyte) (Fig. 1) [13]. Due to its great economical, ecological and research value, Pyropia has been recognized as a model seaweed among marine plants [14, 15].

Extensive surveys have explored the physical reaction of Pyropia to rising $\mathrm{CO}_{2}$, indicating that elevated $\mathrm{CO}_{2}$ concentration (1000-1200 ppm) can enhance growth of Pyropia yezoensis [16, 17]; moreover, inorganic carbon (Ci) uptake styles differ between sporophytes and gametophytes. For instance, Yue et al. and $\mathrm{Li}$ et al. reported that gametophytes of $P$. yezoensis utilize $\mathrm{HCO}_{3}{ }^{-}$via extracellular carbonate anhydrase (eCA), but exhibit weak ability to directly use $\mathrm{HCO}_{3}{ }^{-}[5,18]$. Luo et al. indicated that sporophytes absorb $\mathrm{Ci}$ through active transport of $\mathrm{HCO}_{3}{ }^{-}$and $\mathrm{CO}_{2}$ [19]. By contrast, data from Expressed Sequence Tag (EST) and transcriptome studies suggest the possible existence of a C4-like pathway in P. yezoensis and Pyropia haitanensis, but whether this functions in $P$. yezoensis remains unknown [20-22].

To explore CCMs in P. yezoensis, we cultivated gametophytes and sporophytes under three different $\mathrm{Ci}$ conditions by adjusting the amount of $\mathrm{NaHCO}_{3}$ in artificial seawater. We tracked their growth, transcriptome and relative enzyme activities under different $\mathrm{Ci}$ conditions. Our results provide explanations for the divergence of CCMs between the two life stages of $P$. yezoensis.

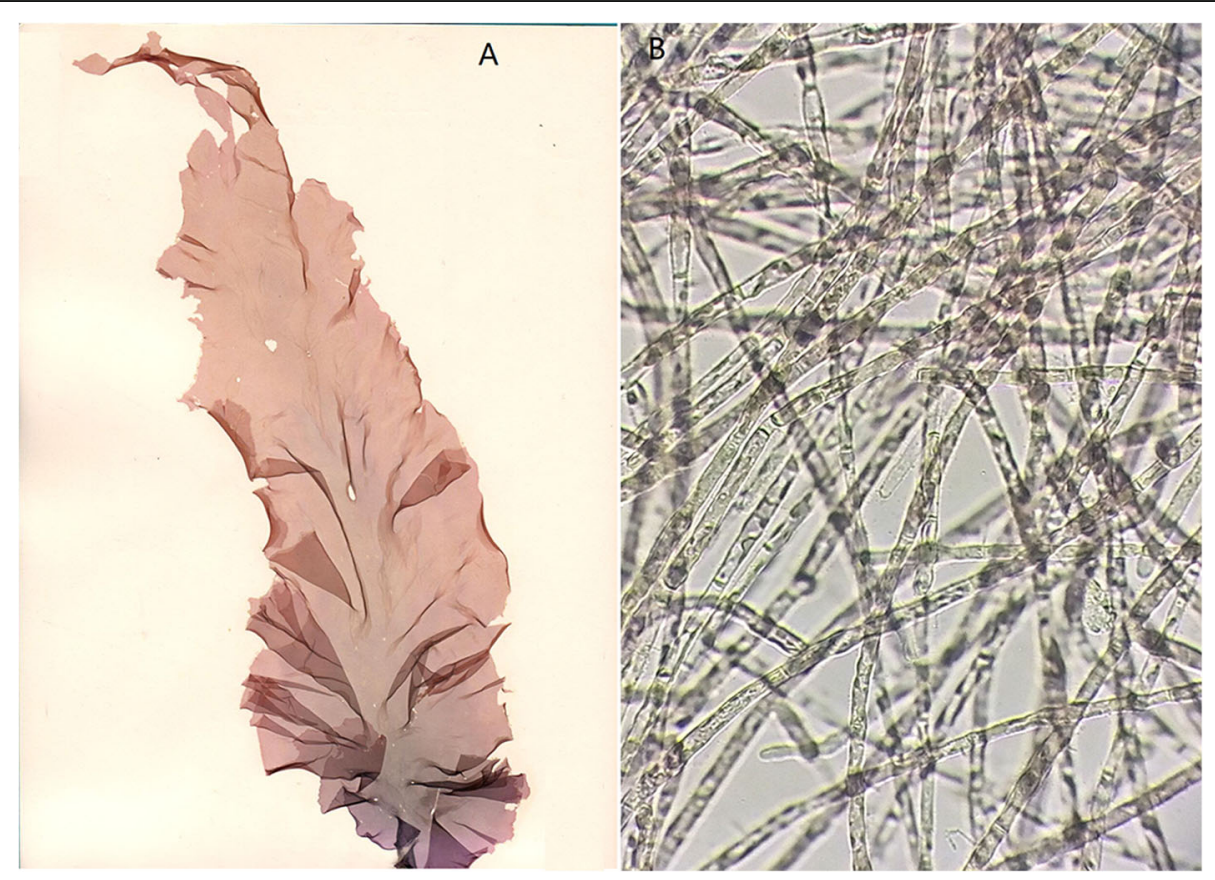

Fig. 1 The photos of leafy thalli (gametophytes) and filamentous thalli (sporophytes). a. leafy thalli. b. filamentous thalli 


\section{Results}

Physiological responses and change of $\mathrm{pH}$ under different Ci conditions

We tracked the $\mathrm{pH}$ of water and physiological characteristics of the two different $P$. yezoensis life cycle stages under culture conditions with different $\mathrm{Ci}$.

In sporophytes, $\mathrm{pH}$ ranged from $8.03 \pm 0.03$ to $8.64 \pm$ 0.02 and $8.59 \pm 0.03$ under high carbon $(\mathrm{HC})$ and normal carbon (NC) conditions, respectively. Under low carbon (LC), pH ranged from $8.00 \pm 0.03$ to $8.32 \pm 0.03$ (Fig. 2). Under LC, photosynthetic efficiency was around $17.75 \pm$ $0.1 \%$ lower than that under $\mathrm{NC}$, while it was enhanced by about $14.11 \pm 0.08 \%$ under $\mathrm{HC}$ compared with $\mathrm{NC}$, as indicated by changes in photosystem II (YII) (Fig. 2).

In gametophytes, the $\mathrm{pH}$ ranged from $8.04 \pm 0.02$ to $8.78 \pm 0.03$ under $\mathrm{HC}$, from $8.02 \pm 0.02$ to $8.65 \pm 0.04$ under NC and from $8.02 \pm 0.03$ to $8.4 \pm 0.02$ under LC (Fig. 2). Photosynthetic efficiency was almost $5.91 \pm$ $0.07 \%$ lower under LC than under NC, while it was enhanced by $16.77 \pm 0.08 \%$ under $\mathrm{HC}$ compared with that under NC (Fig. 2).

\section{Transmission electron microscopy (TEM) observation of} cells from the two life stages under three $\mathrm{Ci}$ conditions Both gametophytes and sporophytes of P. yezoensis exhibited significant changes in the amount of starch and number of chloroplast-localized plastoglobuli, and even pyrenoid structure, with changing environmental conditions (Fig. 3). After culture for $54 \mathrm{~h}$

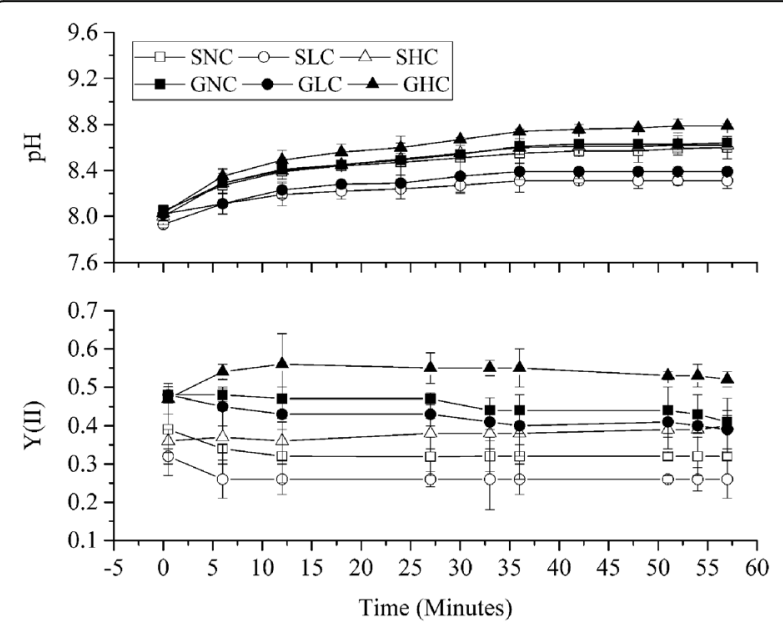

Fig. $2 \mathrm{pH}$ and $\mathrm{Yll}$ changes in gametophytes and sporophytes of $P$. yezoensis under different Ci conditions. SNC, SHC and SLC indicate sporophytes cultivated under normal carbon (NC), high carbon (HC) and low carbon (LC) conditions, respectively. GNC, GHC and GLC indicate gametophytes cultivated under NC, HC and LC conditions, respectively. a. $\mathrm{pH}$ change in gametophytes and sporophytes under different Ci conditions. b. YII change in gametophytes and sporophytes under different $\mathrm{Ci}$ conditions. Results are represented as mean \pm standard deviation under LC, starch was undetectable in cells of both gametophytes and sporophytes, but the number of plastoglobuli in sporophytes increased from 1 to 2 in each cell under $\mathrm{NC}$ to 2-7 under LC. The number of plastoglobuli in gametophytes increased from 2 to 6 in each cell under NC to 2-20 under LC.

Under HC, cells of the two life stages had dramatically more starch than cells growing under NC, usually distributed between chloroplasts in sporophytes but outside of chloroplasts in gametophytes. Plastoglobuli obviously increased in these two life stages under $\mathrm{HC}$, with their number increasing to 7-20 in each sporophyte cell and 10-40 in each gametophyte cell. Under NC, we observed a small amount of starch in the cells of sporophytes but barely any in gametophytes. Pyrenoid structure in gametophytes was loose and there were many ribosomes spread throughout the cytoplasm, while in sporophytes, pyrenoid structure was relatively tight and there were fewer ribosomes than in gametophytes.

\section{Illumina sequencing, de novo assembly and annotation}

To explore the CCM of P. yezoensis, we cultivated gametophytes and sporophytes under different $\mathrm{Ci}$ conditions and constructed 18 cDNA libraries (generated from three biological replicates of the two life stages under the three treatments). Using Illumina Hiseq sequencing technology, each reaction can yield $2 \times 150$ bp independent reads from either end of a DNA fragment. We obtained high-quality clean reads accounting for more than 97.83\% of the raw reads (Additional file 1, Table S1).

After assembling the high-quality clean reads from the high-throughput sequencing data, 182,564 unigenes were identified with a contig N50 size of $945 \mathrm{bp}$ and average unigene size of $837 \mathrm{bp}$ (Table 1). The length of these assembled unigenes ranged from 200 to $42,138 \mathrm{bp}$. Unigenes with lengths between 401 and $600 \mathrm{bp}$ were predominant, comprising approximately $36.54 \%$ of the total number of unigenes; the next most abundant size class was $601-1000 \mathrm{bp}$, constituting $27 \%$ of the total unigenes (Additional file 2, Fig. S1). Both the number and the average length of unigenes were higher than those in reported transcriptome data. Yang [23] obtained 31,538 unigenes with an average length $419 \mathrm{nt}$, and Xie [22] obtained 24,575 unigenes with an average length of $645 \mathrm{bp}$ in P. haitanensis. More recently, Wang obtained 34,465 unigenes in P. haitanensis [24].

We performed BLAST analysis on all 182,564 unigenes using the following databases: NCBI non-redundant protein sequences (Nr), Swiss-Prot, Kyoto Encyclopedia of Genes and Genomes database (KEGG), and Clusters of Orthologous Groups of proteins (COG). We found 59, 825 (32.77\%), 59,327 (32.49\%) and 53,110 (32.5\%) unigenes in Swiss-Prot, Nr, and KEGG, respectively (Additional file 3, Table S2). These results might be due to a 


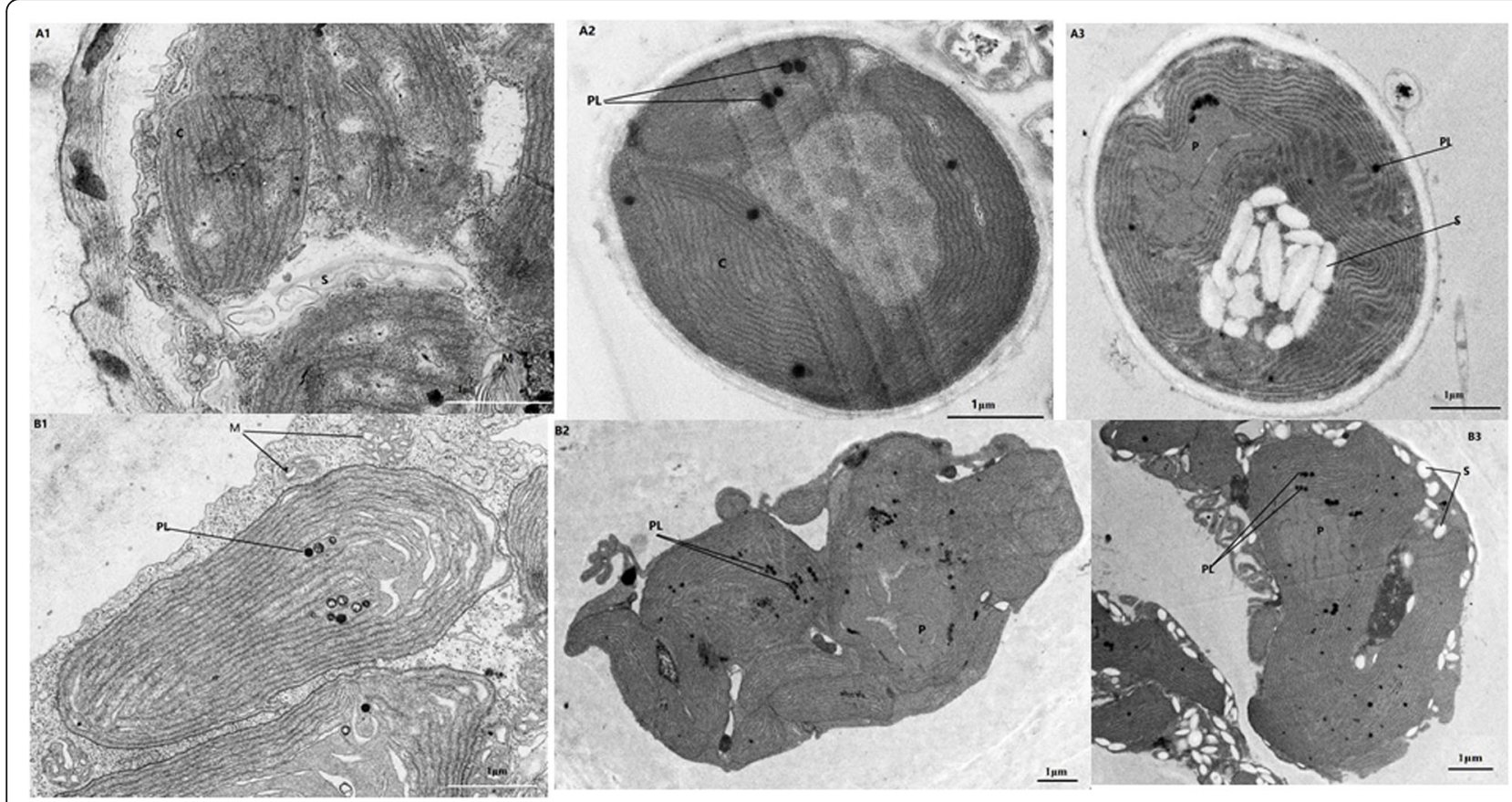

Fig. 3 Transmission electron microscope images of sporophyte $(\mathbf{A})$ and gametophyte $(\mathbf{B})$ cells of $P$. yezoensis under three $\mathrm{Ci}$ conditions. Sporophytes cultivated under NC (A1), LC (A2) and HC (A3); gametophytes cultivated under NC (B1), LC (B2) and HC (B3). PL: plastoglobulus; C: chloroplast; M: mitochondrion; S: starch

lack of complete genome information for $P$. yezoensis. Although genome sequences of $P$. yezoensis are freely available, they are either incomplete or lack annotation [25].

All these data indicated that the RNA-seq data met the quality standard for further analysis. After primary analysis, we identified around 275 unigenes related to CCM pathways.

\section{Induction of BCT and CA under different ci indicates the presence of a biophysical CCM}

We identified a very large number of CA unigenes in this transcriptome. IDs for some of the $C A$ unigenes, their identity in $\mathrm{Nr}$ and Swiss-Prot, and protein subtypes are listed in Additional file 4, Table S3. Three CA unigenes, DN38784_c0_g1 (beta-), DN 99529_c0_g1 (beta-) and DN105005_c0_g1 (alpha-), the former predicted to

Table 1 summary of Trinity assembly of the RNA-seq data of $P$. yezoensis

\begin{tabular}{ll}
\hline Total unigenes num:: & 182,564 \\
Total unigenes length: & $152,921,448$ \\
Total isoform num. & 202,495 \\
Total isoform length & $181,907,159$ \\
Average Unigene length: & 837.631997546066 \\
Largest unigene: & 42,138 \\
N50: & 945 \\
\hline
\end{tabular}

be located in the chloroplast and the other two in other cell positions (Additional file 5, Table S4), were upregulated under LC compared with NC. Transcripts of DN105005_c0_g1 increased by 2.08- and 1.1-fold in gametophytes and sporophytes under LC compared with $\mathrm{NC}$, respectively. Such induction of specific CAs by low $\mathrm{HCO}_{3}{ }^{-}$stress suggests an active biophysical CCM. Moreover, DN38784_c0_g1, DN 99529_c0_g1 and DN50495 _c0_g1 (alpha-), expression levels in gametophytes were significantly higher (over 10 times or even over 100 times) than those in sporophytes under the three $\mathrm{Ci}$ conditions, and the divergence was obvious (Fig. 4). In addition, some other CA unigenes, such as DN127900_c0_g1 (gamma-) and DN87784_c0_g1 (gamma-), predicted to be located in the mitochondrion (Additional file 6, Table S4), showed very low RPKM (reads per kilobase of exon model per million mapped reads) values in sporophytes and undetectable values in gametophytes under these three $\mathrm{Ci}$ conditions (Fig. 4).

Anion exchange proteins and $\mathrm{ABC}$-transporters may play the role of bicarbonate transporters, as indicated from the transcriptome. Expression of DN101765_c1_g1, a putative Band 3 anion transporter sharing $58 \%$ amino acid sequence identity with its known counterparts from Porphyridium purpureum (KAA8497371) and Gracilariopsis chorda (PXF50105), was increased by 0.4- and 0.5fold in sporophytes and gametophytes, respectively, under LC compared with NC. Expression of a putative 


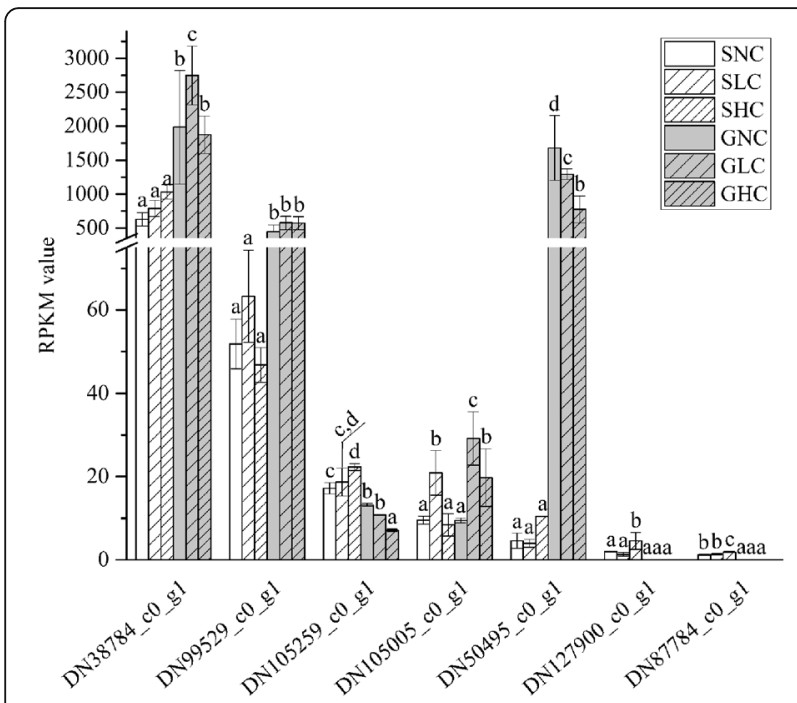

Fig. 4 RPKM values of some CA unigenes in gametophytes and sporophytes of $P$. yezoensis under three $\mathrm{Ci}$ conditions. Data represent the mean \pm standard deviation from three biological replicates. Means followed by same lowercase letters are not significantly different at $p \leq 0.05$ by one-way ANOVA and Tukey's test. Unigene IDs are DN38784_c0_g1, DN99529_c0_g1, DN105259_c0_g1, DN105005_c0_g1, DN50495_c0_g1, DN127900_c0_g1, and DN87784_C0_g1. SNC, SLC, SHC, GNC, GLC and GHC are as in Fig. 1

anion exchange protein, DN107803_c0_g1, was increased 0.36- and 0.65-fold in sporophytes and gametophytes, respectively, under LC compared with NC.

In addition, transcripts of several ABC-transporters (105272_c0_g1, 109304_c3_g1) were upregulated under LC compared with $\mathrm{NC}$ in the two life cycles; moreover, the RPKM values of these unigenes in sporophytes were significantly higher than those in gametophytes.

\section{Increased transcript abundance and enzyme activity of C4-like enzymes under different $\mathrm{Ci}$ indicates an active biochemical CCM}

Key genes involved in the C4-pathway were all identified in this transcriptome, and some unigenes encoding these key enzymes are listed in Additional file 4, Table S3. The subcellular location of key enzymes involved in the C4pathway was predicted using different prediction servers and the results are shown in Additional file 5, Table S4.

BlastX search showed that DN107354_c0_g1 had 100\% amino acid sequence identity with PEPC in P. yezoensis (accession no. AIT70077); it was predicted to be located in neither the mitochondrion nor the chloroplast, and may be located in the cytosol (Additional file 5, Table S4). We identified DN101889_c0_g3 and DN101912_c0_ g1 as transcripts of PEPCK due to very high amino acid identity (64 to $77 \%$ ), and predicted them to be targeted to mitochondria. DN141134_c0_g1, DN14534_c0_g1 and DN87488_c0_g1 were identified as putative unigenes of pyruvate phosphate dikinase (PPDK); the former two were predicted to be located in the chloroplast, and the latter was predicted to be located in the mitochondrion (Table S4). DN74954_c0_g1, DN34191_ c0_g1 and DN50799_c0_g1 encode malate dehydrogenase $(M D H)$ and were predicted to target to the mitochondria, another cellular position and the chloroplast, respectively (Table S4). We also identified a few unigenes encoding $M E$, such as DN75319_c0_g1 and DN53078_c0_g1. DN15039_c0_g1 and DN105351_c0_g1 are pyruvate carboxylase $(P Y C)$ unigenes, and the former was predicted to be located in the mitochondria while the latter localized to another position in the cell (Table S4).

The expression of these unigenes involved in biochemical CCM under different $\mathrm{Ci}$ conditions is indicated in RPKM and shown in Fig. 5a. Under HC conditions, the expression of $M D H, P P D K$ and PEPCK unigenes was upregulated, in sporophytes, moreover, the divergency from expression is obvious, although the RPKM value was low (Fig. 5a). The $M D H$ (DN74954_c0_g1), PPDK (DN14534_c0_g1) and PEPCK (DN101889_c0_g3) unigene were induced by $1.1-$, 32- and 1.45-fold, respectively, under HC compared with NC in sporophytes. The expression of these three genes in gametophytes was so low that they were almost undetectable. Meanwhile, the expression of PEPC was downregulated under $\mathrm{HC}$ compared with $\mathrm{NC}$ in these two life stages, and decreased 0.25 - and 0.45 -fold in sporophytes and gametophytes (Fig. 5a). Under LC conditions, the expression of PEPC and $P P D K$ was upregulated, and increased 0.35 - and 1.56-fold, respectively, compared with that under $\mathrm{NC}$ conditions in sporophytes. While the expression of $M D H$ was downregulated and decreased 0.57 -fold in sporophytes. The expression of $M E$ and $P Y C$ unigenes showed no obvious difference under different $\mathrm{Ci}$ concentrations in the two life stages (Fig. 5a).

Changes in gene expression for individual targets were validated using real-time fluorescent quantitative reverse - transcription PCR (qRT-PCR) (Fig. 5b). Among eight detected unigenes, most genes showed a similar expression tendency to that revealed by transcriptome data, except for the PEPC unigene (DN107354c0g1). This was upregulated in gametophytes under LC compared with $\mathrm{NC}$, while the transcriptome indicated no divergence between LC and NC conditions.

We detected the activity of key enzymes involved in this pathway under the different $\mathrm{Ci}$ conditions (Fig. 6a). PEPC enzyme activity under HC was 119.3 and 103.9 $\mathrm{nmol} / \mathrm{min} / \mathrm{g} \mathrm{FW}$ in sporophytes and gametophytes, respectively, higher than under LC and NC conditions. PEPCK showed very high decarboxylating activity in the two life cycles, greater than $5400 \mathrm{nmol} / \mathrm{min} / \mathrm{g}$ FW. The enzyme activity of PEPCK under $\mathrm{HC}$ in gametophytes was a little higher than that in sporophytes, 6076.2 and 

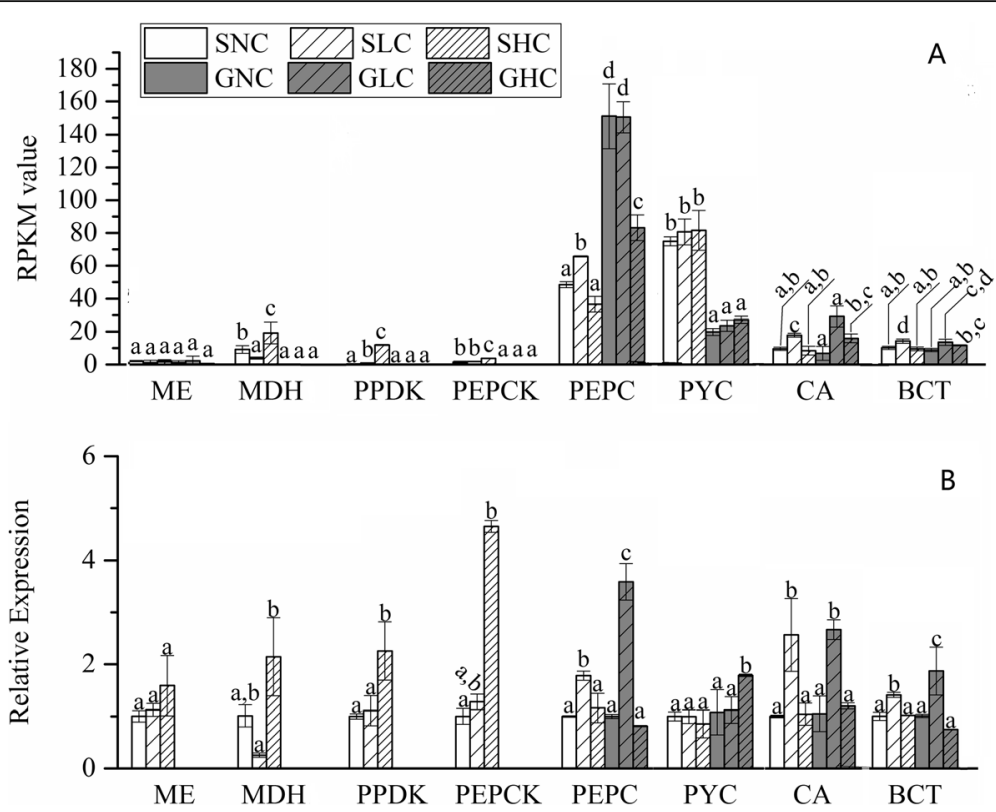

Fig. 5 Expression levels of some key genes involved in biochemical CCM based on RNA-Seq assays $(\mathbf{A})$ and relative expression levels verified by qPCR (B) in gametophytes and sporophytes of $P$. yezoensis under three $\mathrm{Ci}$ conditions. Data represent the mean \pm standard deviation from three biological replicates. Means followed by same lowercase letters are not significantly different at $p \leq 0.05$ by one-way ANOVA and Tukey's test. ME (DN53078_c0_g1), MDH (DN74954_C0_g1)9, PPDK (DN14534_c0_g1), PEPCK (DN101889_c0_g3), PEPC (DN107354_c0_g1), PYC (DN105351_C0_g1), CA (DN105005_C0_g1), BCT (DN101765_c1_g1)

$6238.7 \mathrm{nmol} / \mathrm{min} / \mathrm{g} \mathrm{FW}$, respectively. Enzyme activity of PPDK under $\mathrm{HC}$ was higher than that under $\mathrm{LC}$ and NC. Moreover, PPDKase activity in sporophytes was about onefold higher than that in gametophytes. Reduction activity of NAD-MDH, which reduces oxaloacetate (OAA) into malate (MAL), was also detected; it was commonly higher in sporophytes than in gametophytes and was usually higher under $\mathrm{HC}$ relative to $\mathrm{LC}$ and $\mathrm{NC}$ : 835.6 and $688.5 \mathrm{nmol} / \mathrm{min} / \mathrm{g} \mathrm{FW}$ in sporophytes and gametophytes under HC, respectively. NADP-MEase activity in sporophytes was higher than that in gametophytes under $\mathrm{HC}$, at 347.7 and $293.3 \mathrm{nmol} / \mathrm{min} / \mathrm{g} \mathrm{FW}$,

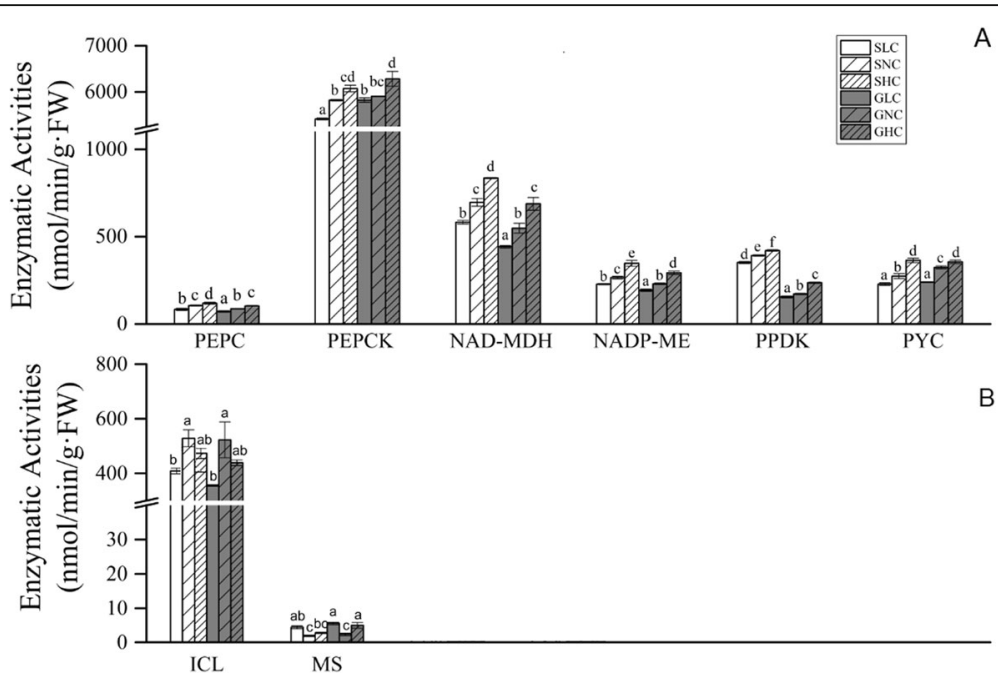

Fig. 6 Activities of key enzymes involved in biochemical CCM (A) and the glyoxylate cycles (B) in gametophytes and sporophytes of P. yezoensis under different $\mathrm{Ci}$ conditions. Data represent the mean \pm standard deviation from three biological replicates. Means followed by same lowercase letters are not significantly different at $p \leq 0.05$ by one-way ANOVA and Tukey's test. SNC, SLC, SHC, GNC, GLC and GHC are as in Fig. 1 
respectively. PYCase activity in gametophytes was a little higher than that in sporophytes under $\mathrm{NC}$, at 323.7 and $274.5 \mathrm{nmol} / \mathrm{min} / \mathrm{g} \mathrm{FW}$, respectively, while it was similar under $\mathrm{HC}$ in both life stages, at 356.8 and $364.6 \mathrm{nmol} /$ $\mathrm{min} / \mathrm{g} \mathrm{FW}$.

We also detected the activity of some key enzymes involved in the glyoxylate cycle (Fig. 6b). ICL and MS, the key enzymes involved in the glyoxylate cycle, showed dramatically different activities. The highest activity of ICL was observed under NC, at about $520 \mathrm{nmol} / \mathrm{min} / \mathrm{g}$ FW in the two life stages. The lowest activity of ICL was 355 and $423 \mathrm{nmol} / \mathrm{min} / \mathrm{g} \mathrm{FW}$ in the gametophytes and sporophytes, under LC. The activity of MS was very low and around $3 \mathrm{nmol} / \mathrm{min} / \mathrm{g}$ FW under three $\mathrm{Ci}$ conditions.

\section{Discussion}

\section{Physical characteristics of the two life cycles under} different $\mathrm{Ci}$ conditions

The effective photochemical quantum yield of photosystem II (YII) is directly related to the $\mathrm{CO}_{2}$ assimilation rate and represents the photosystem II state [26, 27]. As shown in Fig. 1, YII in gametophytes was higher than that in sporophytes under the same culture conditions. Huan (2018) studied the response of the photosynthetic reaction in the two life stages of $P$. yezoensis to increasing $\mathrm{CO}_{2}$, and found that YII in gametophytes was enhanced as $\mathrm{CO}_{2}$ increased; however, there were no significant differences in YII of sporophytes [28]. Wang (2019) reported that net photosynthetic rates $(\mathrm{Pn})$ of thalli gametophytes were about 2.9 times those of conchocelis sporophytes of $P$. haitanensis at $\mathrm{pH} 8.0$ [29]. All these results suggest that gametophytes of Pyropia usually have a higher photosynthetic rate than sporophytes under the same culture conditions. Interestingly, LC had more effect on sporophytes than on gametophytes, indicated by reduced photosynthetic efficiency (YII) under LC conditions.

Among the conditions affecting photosynthesis in aquatic plants is the hydrogen ion concentration of the growth environment. The $\mathrm{pH}$ of the medium determines the ratios of $\mathrm{H}_{2} \mathrm{CO}_{3}, \mathrm{HCO}_{3}{ }^{-}$and $\mathrm{CO}_{3}{ }^{-}$, and then influences photosynthetic rate [30]. Since LC had a more obvious negative effect on YII in sporophytes than in gametophytes, $\mathrm{pH}$ change under LC culture was comparatively less for sporophytes relative to gametophytes. Under HC conditions, the photosynthetic efficiency of gametophytes was higher than that of sporophytes, so the $\mathrm{pH}$ of $\mathrm{HC}$ medium rose more quickly for gametophytes, accordingly. These results indicated that the reactions of sporophytes and gametophytes to the change of $\mathrm{Ci}$ concentration are different; sporophytes are more sensitive to the $\mathrm{LC}$ relative to gametophytes, while properly elevated $\mathrm{Ci}$ (such as $4 \mathrm{mM} \mathrm{HCO}_{3}{ }^{-}$in seawater) enhances the photosynthetic efficiency of photosystem II in gametophytes more than in sporophytes.

The physiological state of algae is closely related to its metabolites. When P. yezoensis was cultured under LC, starch was consumed, as shown in Fig. 3. He et al. (2002) reported that starch in macroalgae was consumed first when macroalgae were in a hungry state [31]. When $P$. yezoensis was cultivated under $\mathrm{HC}$ conditions, more starch was observed (Fig. 3). Plastoglobuli, also called osmiophilic globuli, are plastid-localized lipoprotein particles [32-34]. Interestingly, we observed that the number of plastoglobuli changed in the two different life stages under $\mathrm{HC}$ and LC compared NC. The reason for this phenomenon corresponds to the role of plastoglobuli. It has been proved that plastoglobuli play an active role in metabolic and stressresponse pathways, and are a metabolic intersection between different plastid compartments [35, 36].

\section{Biophysical CCM in the two different life cycles of $P$. yezoensis}

Facing the phenomenon of rising global $\mathrm{CO}_{2}$, researchers are paying more attention to the inorganic carbonate utilization of macroalgae, including Pyropia. Work has been conducted to explore the physiological reaction to rising $\mathrm{CO}_{2}$, the $\mathrm{pH}$ compensation point, and the physiological reaction after adding different types of inhibitors $[19,37,38]$. The $\mathrm{pH}$ compensation point of gametophytes and sporophytes of $P$. haitanensis is $\mathrm{pH} 9.9$ and 9.95 , respectively, and of gametophytes of $P$. yezoensis is $\mathrm{pH} 9.65[5,19]$. High $\mathrm{pH}$ compensation point corresponds to the presence of CCMs [39]. However, despite the above inferences, we still lack direct molecular evidence. In this study, we found a large number of unigenes encoding CA and some unigenes encoding anion transporter protein, which maybe play roles in transporting $\mathrm{HCO}_{3}{ }^{-}$into cells from the external environment. Since $\mathrm{HCO}_{3}{ }^{-}$is not freely permeable across the lipid bilayer of biological membranes, it is either transported by membrane transporter proteins or obtained in the form of $\mathrm{CO}_{2}$, which is then converted by periplasmic CA [40].

$\mathrm{HCO}_{3}{ }^{-}$uptake in the two different Pyropia life stages has been elucidated by physiological reactions to different types of inhibitors, such as acetazolamide (AZ), eCA inhibitor, ethoxyzolamide (EZ), iCA inhibitor and an inhibitor of the $\mathrm{HCO}_{3}{ }^{-}$transporter, 4,4' -diisothiocyanatostilbene-2,2'-disulfonic acid (DIDS). Luo and his coworkers (2002) examined the inhibitory effect of AZ, DIDS and vanadate, an inhibitor of ATPase associated with the plasma membrane, on sporophytes of $P$. haitanensis. They showed inhibitory rates of 25.3 and $71.3 \%$, respectively, after adding $\mathrm{AZ}$ and vanadate, and inferred that eCA is not an important part of Ci uptake in P. haitanensis conchocelis, with most $\mathrm{Ci}$ absorption occurring through active transport of $\mathrm{HCO}_{3}{ }^{-}$and $\mathrm{CO}_{2}$ [19]. Later, $\mathrm{Li}$ and his coworkers (2016) suggested that the 
gametophytes of $P$. yezoensis show active $\mathrm{HCO}_{3}{ }^{-}$uptake by studying their reaction to enhanced $\mathrm{CO}_{2}$ in the atmosphere [5]. Recently, Wang (2019) studied the physiological reaction to $\mathrm{Ci}$ utilization between gametophytes and sporophytes of $P$. haitanensis and found that the Pn of thallus was significantly inhibited by AZ and EZ. For conchocelis, inhibition by EZ was greater than that by AZ. Inhibition of conchocelis by DIDS was greater than that of thallus. All these results indicate that iCA and eCA play essential roles in $\mathrm{HCO}_{3}{ }^{-}$utilization in gametophytes, while iCA is more important than $\mathrm{eCA}$ in sporophytes. At the same time, the absorption of $\mathrm{HCO}_{3}{ }^{-}$via the DIDS-sensitive anion transport protein is less important in gametophytes than in sporophytes [29].

Limitations of subcellular location software and servers prevented us from defining the eCA unigenes; thus, we could not determine their RNA expression levels under different $\mathrm{Ci}$ conditions. We detected a higher abundance of some chloroplast-targeted CA genes, for instance DN38784_c0_g1 and DN50495_c0_g1, in gametophytes than in sporophytes (Fig. 4), which suggested that biophysical CCMs play a more important role in gametophytes relative to sporophytes.

We identified some unigenes encoding anion exchange proteins and $\mathrm{ABC}$-transporters, and these were upregulated under LC compared with NC. Moreover, the abundance of these genes encoding bicarbonate transporters was higher in sporophytes relative to gametophytes. These data are in agreement with evidence from inhibitory experiments that anion exchange proteins and $\mathrm{ABC}$ - transporters make a great contribution to $\mathrm{HCO}_{3}{ }^{-}$ transportation in sporophytes of $P$. yezoensis.

BCTs are divergent within the microalgae and macroalgae. In Macrocystis pyrifera (Phaeophyta), anion exchange protein plays the main role in bicarbonate uptake, while in microalgae, such as Nannochloropsis oceanica and Chlamydomonas reinhardtii, ABCtransporters play an essential role in $\mathrm{HCO}_{3}{ }^{-}$transportation [41-43]. In Phaeodactylum tricornutum, the solute carrier family is the $\mathrm{HCO}_{3}{ }^{-}$transporter [44].

\section{Biochemical CCM in $P$. yezoensis}

Besides the C3 pathway, a C4-like pathway might exist in Pyropia. Fan et al. (2007) constructed an EST library of $P$. haitanensis sporophytes and found abundant PEPCK ESTs; they primarily inferred that a C4-like pathway might exist in sporophytes of $P$. haitanensis [21]. Later, genes involved in the C4-like pathway were identified in P. yezoensis, except PPDK [20]. Xie and his coworkers (2013) obtained the transcriptomes of gametophytes and sporophytes of $P$. haitanensis and found some key genes involved in the C4-pathway, but no unigenes encoding PPDK or $M D H$. They inferred that the C4-like pathway plays a role in sporophytes, according to RNA relative expression levels of PEPCK and PEPC [23]. In fact, there has not been enough direct evidence so far to support this opinion.

In our work, we not only found all the key genes involved in the C4-like pathway, including unigenes encoding $P P D K$, but we also detected the activity of these enzymes under different $\mathrm{Ci}$ conditions. At the transcript level, we found that each gene involved in the C4-like pathway had a few unigenes (Table S3), which may indicate that most genes belong to multicopy gene families. As Fig. 5 shows, unigenes involved in the C4-like pathway showed different responses when $\mathrm{Ci}$ conditions shifted from NC to HC/LC. Although the RNA abundance of some unigenes corresponding to PPDK or $P E P C K$ genes was very low in the two life stages, there was obvious divergence in expression when $\mathrm{Ci}$ conditions shifted from NC to HC/LC.

At the enzyme activity level, key enzymes involved in the C4-like pathway showed similar tendencies, with higher activity under $\mathrm{HC}$ than under the other $\mathrm{Ci}$ conditions. From these results, we primarily suggest that the expression of these key genes under different $\mathrm{Ci}$ conditions does not correspond to relative enzyme activity.

High PEPCKase decarboxylation activity but low PEPCase activity was observed in this work. This situation has also been observed in other macroalgae. Xu (1991) reported this phenomenon in brown Laminaria japonica [45]. Later, Shao (2019) also found very high PEPCK decarboxylation activity under $\mathrm{HC}$ conditions $\left(0.1 \mathrm{M} \mathrm{KHCO}_{3}\right)$ in Saccharina japonica, but they did not detect PEPCase activity [46]. He (2013) reported that PEPCKase showed higher decarboxylation activity but lower carboxylation activity in P. haitanensis [47]. Kremer and Küppers found that PEPCase activities were very low or undetectable in some red, green and brown macroalgae [48].

Since low PEPCase activity exists in most macroalgae, we investigated another carboxylating enzyme - PYC. PYC functions in non-photosynthetic organisms, but in recent years, $P Y C$ genes have been found in various aquatic phototrophs, such as $C$. reinhardtii and Chlorella variabilis [49,50]. Tsuji and his coworkers identified a plastid-located PYC and proposed that EhPYC1 contributes to active beta-carboxylation in Emiliania huxleyi, indicating a novel pathway for the production of $\mathrm{C} 4 \mathrm{com}-$ pounds [50]. In our work, PYCase showed higher carboxylating activity than PEPCase, thus providing the OAA for PEPCKase decarboxylation. That is to say, PYC plays the major carboxylation role in biochemical CCM in $P$. yezoensis. This is the first report of this to our knowledge.

OAA and MAL are also parts of the peroxisome glyoxylate cycle, at which carbohydrates are synthesized from $\mathrm{C} 2$ compounds $[51,52]$. The key enzyme activities of the glyoxylate cycle, ICL and MS, were investigated. Higher ICL activity and lower MS activity indicated that the contribution of the glyoxylate cycle generating MAL is 
weak. However, NAD-MDHase showed high reduction activity in this study, and generated MAL. MAL in the cytosol can enter into the mitochondrion for use in other pathways, such as the TCA cycle and C4-like CCM pathway.

Combining our predicted subcellular location results, enzymic activity and the putative $\mathrm{C} 4$ pathway generated from the transcriptome, we constructed an overview of the biochemical CCM of P. yezoensis (Fig. 7). Of course, the precise subcellular location needs to be proved by location experiments. We primarily suggest that the C4like pathway might be located in the mitochondrion and belong to the PEPCK subtype. Some enzymes involved in this pathway, such as PEPC and MDH, have cytosollocated isoforms and may play roles in the cytosol. The C4-like pathway not only plays a role in sporophytes, but also plays a role in gametophytes under $\mathrm{NC}$ and $\mathrm{HC}$ conditions, unlike the previous hypothesis.

\section{Conclusions}

The CCM in P. yezoensis includes biophysical CCM and biochemical CCM, and they play an essential role for the growth of $P$. yezoensis. The two CCMs perform different roles according to environmental $\mathrm{Ci}$ concentrations. The biophysical CCM plays a more important role in gametophytes than in sporophytes, and the C4-like pathway also plays a role under high $\mathrm{Ci}$ conditions, explaining why gametophytes have higher photosynthesis rate than sporophytes. Moreover, PYC plays the major carboxylation role in biochemical CCM in P. yezoensis.

\section{Methods}

\section{Algal materials}

Wild resources of Pyropia yezoensis (Ueda) M. S. Hwang \& H. G. Choi was originally collected in Qingdao, Shandong Province, China, and they are permitted by local government to collect. Then sporophytes of $P$. yezoensis were stored in the algae collection in the Institute of Oceanology, Chinese Academy of Sciences, Qingdao, China, and gametophytes of this species were generated from sporophytes under laboratory conditions. Before incubating in artificial seawater with different dissolved $\mathrm{Ci}$ concentrations, thallus gametophytes and filamentous sporophytes were cultured in Provasoli's enriched seawater medium at $18{ }^{\circ} \mathrm{C}$ under $12 \mathrm{~h}$ light: $12 \mathrm{~h}$ dark at $30 \mu \mathrm{mol} / \mathrm{m}^{2} / \mathrm{s}$.

Artificial seawater (g/L: $\mathrm{NaCl}$ 20.758, $\mathrm{NaSO}_{4}$ 3.477, $\mathrm{CaCl}_{2} 1, \mathrm{KCl}$ 0.587, $\mathrm{MgCl}_{2} \cdot 6 \mathrm{H}_{2} \mathrm{O}$ 9.359, $\mathrm{NaHCO}_{3}$ 0.17, $\mathrm{KBr} 00845, \mathrm{H}_{3} \mathrm{BO}_{3}$ 0.0225, NaF 0.0027, $\mathrm{SrCl} \cdot 6 \mathrm{H}_{2} \mathrm{O}$ 0.0214 ) was used for $\mathrm{NC}$ conditions. There was no $\mathrm{NaHCO}_{3}$ in artificial seawater representing LC and 4 $\mathrm{mM} \mathrm{HCO}_{3}{ }^{-}(0.34 \mathrm{~g} / \mathrm{L})$ in artificial seawater with $\mathrm{HC}$. $\mathrm{NaHCO}_{3}$ was added to the artificial seawater after autoclaving, and the $\mathrm{pH}$ was then adjusted to around 8.1.

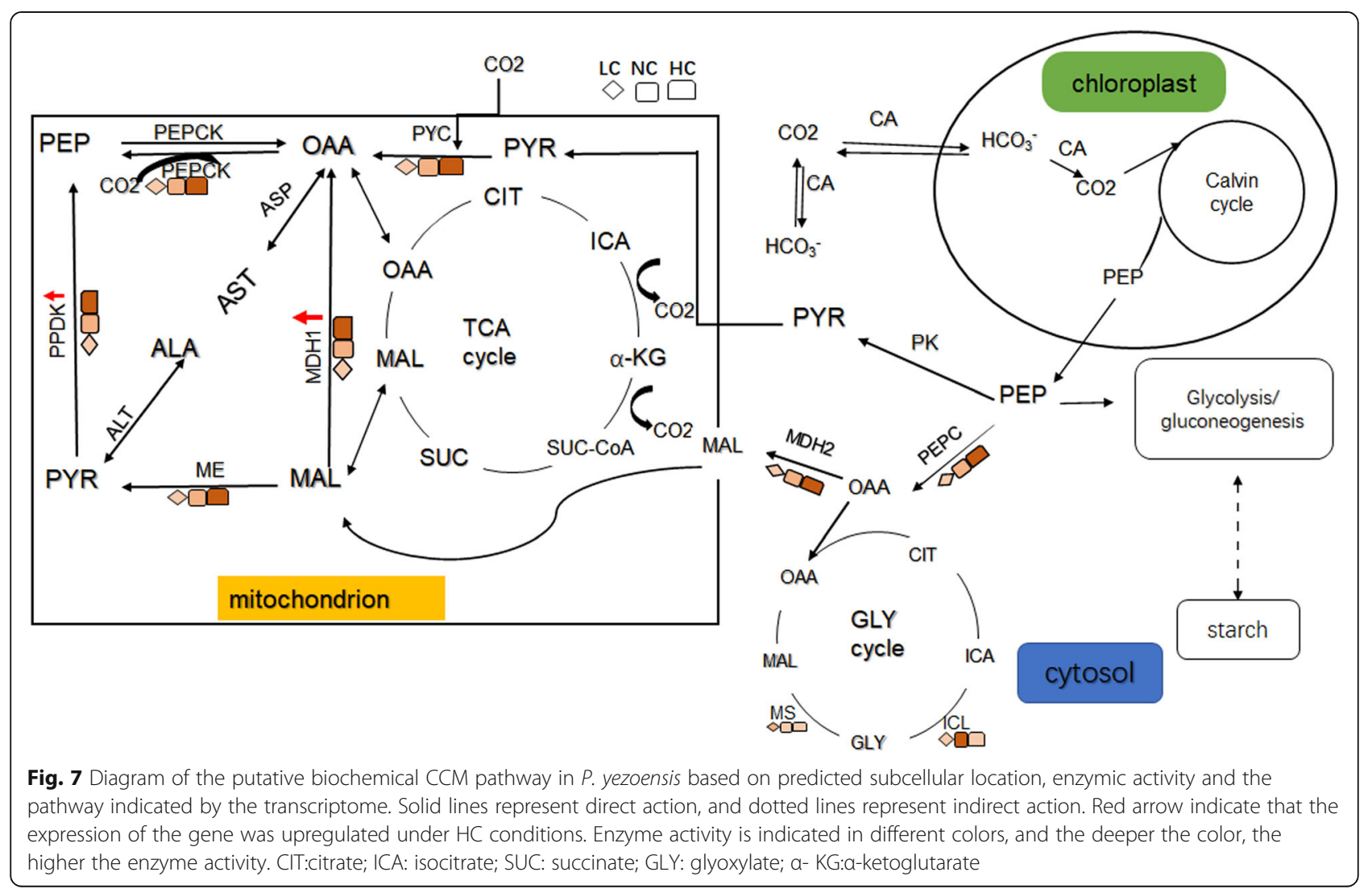


Transcriptome sampling, library construction, sequencing and analysis

Gametophytes and sporophytes were cultured in the three media mentioned above (LC, NC, HC) in a Multicultivator MC 1000-OD (Photon Systems Instruments, Drasov, Czech Republic) with cool white light $(30 \mu \mathrm{mol}$ photons $\left./ \mathrm{m}^{2} / \mathrm{s}\right)$ at $18{ }^{\circ} \mathrm{C}$. Fresh materials $(0.05 \mathrm{~g})$ were inoculated into $80 \mathrm{~mL}$ medium with three biological replicates for each $\mathrm{Ci}$ concentration. To avoid disturbance from outside carbon sources, media were bubbled continuously with mixed gas of high purity nitrogen and oxygen (4:1). After culturing for $54 \mathrm{~h}, 18$ samples were collected for transcriptomic analyses. Total RNA was extracted from each sample using Trizol reagent (Invitrogen, Thermo Scientific, USA). The concentration and purity of total RNA were assessed with spectrophotometers (NanoDrop-1000, Thermo Scientific, USA). Strandnonspecific transcriptome libraries were prepared using a TruseqTM RNA sample prep Kit (Illumina, USA) and sequenced for $2 \times 150$ bp runs (paired-end) using an Illumina HiSeq 2000 at Biozeron Biotech. Co. Ltd., China.

After sequencing, the raw reads datasets were evaluated using Trimmomatic software (http://www.usadellab.org/cms/ uploads/supplementary/Trimmomatic). Adapter sequences and lower-quality reads (shorter than $30 \mathrm{bp}$ or quality score lower than 20) were filtered to obtain high-quality mRNA sequencing reads (Additional file 2, Table S1). The high-quality clean reads from all samples were assembled using Trinity software V2.2.0 (http://trinityrnaseq.sourceforge.net/) to produce an assembly gene set. All of the raw reads generated in this study have been deposited in China national GeneBank (https://db.cngb.org/cnsa/) with accession code CNP0000880.

The assembled gene set was used for BLASTX search $($ BLAST+2.7.1, E Value $\leq 1 \mathrm{e}-5)$ against the NR, Swissprot and KEGG databases for functional annotation. Gene expression under each experimental condition was measured as the number of aligned reads to annotated genes determined by Cufflinks (version 2.0.4) and normalized to RPKM values.

\section{Measurements of photosynthetic parameters and $\mathrm{pH}$}

$\mathrm{pH}$, chlorophyll fluorescence of PSII (YII), maximum quantum yield $(\mathrm{Fv} / \mathrm{Fm})$, and dissolved $\mathrm{CO}_{2}$ and $\mathrm{O}_{2}$ concentrations were detected in real time in a flat-panel photobioreactor (Photobioreactor FMT 150 from Photon System Instruments). Culturing conditions were the same as those of the Multi-cultivator MC 1000-OD bioreactor, with $0.4 \mathrm{~g}$ fresh weight $(\mathrm{FW})$ of $P$. yezoensis gametophytes or sporophytes added to $800 \mathrm{~mL}$ medium. Three biological replicates were conducted.

\section{qRT-PCR assay}

The relative expression levels of genes listed in Table S5 from above mentioned cultures were measured by qRT-
PCR. The protocol for qRT-PCR was performed by standard methods (Roche, Switzerland) as described previously [53], with Eukaryotic initiation factor 4A (EIF4A, TRINITY_DN83248_c0_g1) as an internal reference gene. Triplicate qRT-PCRs were performed for each sample. The relative expression of each gene under $\mathrm{HC} /$ LC conditions was determined by comparing with $\mathrm{NC}$ condition in each group, the sporophyte group and the gametophyte group. Primer pairs used for qRT-PCR analyses are listed in Additional file 6, Table S5.

\section{Statistical analysis}

All the results in this study are shown as mean values \pm standard deviation $(n=3)$. The data were firstly analyzed using oneway ANOVA and then Tukey's test was used for post hoc analysis at the $\alpha=0.05$ significance level. All analyses were carried out using SPSS 18.0 (SPSS Inc., Chicago, Il, USA).

\section{The prediction of subcellular localization of proteins}

To better understand the biochemical CCM pathway of $P$. yezoensis, information of subcellular location of putative proteins involved in this pathway is necessary. Four programs, SignalP, ChloroP, Mitoprot, and TargetP, were used to predict subcellular localization. The SignalP 5.0 server (http:// www.cbs.dtu.dk/services/SignalP/) predicts the presence of signal peptides and the location of their cleavage sites in proteins from Archaea, Bacteria and Eukarya. ChloroP (http:// www.cbs.dtu.dk/services/ChloroP/) predicts the presence of chloroplast transit peptides (cTP) in protein sequences and the location of potential cTP cleavage sites. MitoProt calculates the $\mathrm{N}$-terminal protein region that can support a mitochondrial targeting sequence and the cleavage site [54]. The TargetP-2.0 server (http://www.cbs.dtu.dk/services/TargetP/) predicts the presence of $\mathrm{N}$-terminal presequences: signal peptide, mitochondrial transit peptide, chloroplast transit peptide or thylakoid luminal transit peptide. Results from the four programs were pooled, and locations with higher scores or the same prediction results were chosen as the predicted localization for a particular protein. Unigenes encoding the key enzymes involved in the biochemical CCM pathway are listed in Additional file 5, Table S4.

\section{Measurement of the enzymatic activity involved in C4-like pathway and glyoxylate cycle}

Enzymatic activities of PEPC, PEPCK, PPDK, NADP$\mathrm{ME}, \mathrm{NAD}-\mathrm{MDH}, \mathrm{PYC}, \mathrm{MS}$ and ICL were measured using quantification kits (Keming Biotech, China) according to the user's manual. In the protocol, about 100 mg fresh algal materials were ground on ice, and $1 \mathrm{~mL}$ extraction buffer from the respective kit was added. The mixture was stirred to homogeneity and centrifuged at $4{ }^{\circ} \mathrm{C}, 10,000 \mathrm{~g}$ for $10 \mathrm{~min}$. Supernatants were incubated on ice for further enzyme assays. Enzyme activities were determined using a UV-1800 spectrophotometer by 
measuring the change of absorbance at $340 \mathrm{~nm}$ over 5 min in total volumes of $0.2 \mathrm{~mL}$ and in triplicate. The enzyme activity unit was defined as nmol $\mathrm{NAD}(\mathrm{P}) \mathrm{H}$ oxidation or $\mathrm{NAD}(\mathrm{P})$ + reduced per minute per gram fresh weight. The MS activity was determined by measuring the change of absorbance at $412 \mathrm{~nm}$ according to the protocol of kit.

\section{Transmission Electron microscopy}

Samples were collected in a centrifuge tube after being cultivated for $54 \mathrm{~h}$. Samples were then fixed in a solution of $4 \%$ glutaraldehyde with $0.01 \mathrm{M}$ phosphate buffer, $\mathrm{pH} 7.4$, at $4{ }^{\circ} \mathrm{C}$ and then centrifuged for $10 \mathrm{~min}, 5000 \mathrm{~g}$ at room temperature. Pellets were washed with phosphate buffer, and then postfixed with $1 \%$ osmium tetroxide (Ted Pella INC, California, USA) in phosphate buffer, $\mathrm{pH} 7.4$, for $1.5 \mathrm{~h}$ before washing three times with $0.01 \mathrm{M}$ phosphate buffer at $4{ }^{\circ} \mathrm{C}$. The samples were dehydrated in a series of ethanol from 30 to $100 \%$, infiltrated with acetone (Tieta, Laiyang, China) and epoxy resin (SPI - CHEM, USA) mixture, and embedded and polymerized in epoxy resin. Sections were cut with a Leica EM UC7 ultramicrotome (Leica Microsystems, Germany), stained with citrate and examined with a transmission electron microscope (HT7700, Hitachi, Tokyo, Japan).

\section{Supplementary information}

Supplementary information accompanies this paper at https://doi.org/10. 1186/s12870-020-02629-4.

Additional file 1: Table S1. Statistics of quality control on RNA-seq data of gametophytes and sporophytes samples of $P$. yezoensis under different $\mathrm{Ci}$ conditions.

Additional file 2: Figure S1. Sequence length distribution of transcriptome.

Additional file 3: Table S2. Summary of $P$. yezoensis transcriptome. Additional file 4: Table S3. The identity value and subtype of some unigenes of $P$. yezoensis involved in biochemical and biophysical CCM.

Additional file 5: Table S4. Predicted subcellular localization of some unigenes which encoding the key enzymes involved in biochemical and biophysical CCM in P.yezoensis. The analysis is based on predictions from various computational programs. Abbreviations: Y: Yes; -, not detected; C, chloroplast; M, mitochondrion; O, other; SP, signal peptide.

Additional file 6: Table S5. Primers used for qRT-PCR.

\section{Abbreviations}

ABC transporter: ATP-binding cassette transporter; AZ: Acetazolamide; BCT: Bicarbonate transporters; CA: Carbonic anhydrase; eCA: Extracellular carbonate anhydrase; EST: Expressed sequence tag; CCM: Carbon concentration mechanism; iCA: Internal CA; Ci: Inorganic carbon; HC: High carbon; ICL: Isocitrate lyase; LC: Low carbon; MDH: Malate dehydrogenase; ME: Malic enzyme; MS: Malate synthase; NC: Normal carbon; PEPC: Phosphoenolpyruvate carboxylase; PEPCK: Phosphoenolpyruvate carboxykinase; PPDK: Pyruvate phosphate dikinase; PYC: Pyruvate carboxylase; RPKM: Reads Per kilobase of exon model per million mapped reads; TEM: Transmission electron microscopy

\section{Acknowledgements}

We are grateful to Dr. Wei Zhou (Marine Fisheries Institute of Jiangsu, Nantong, China) for generous help for many years, and we also thank Prof. Jianyi Zhu (Changshu Institute of Technology, Changshu, China) for guidance in the ultrastructure of $P$. yezoensis.

\section{Authors' contributions}

BZ conceived, designed research and analysed the transcriptome data; XX did the physiological experiment and made Tables. XL did the statistical analysis of this work. LH cultivated the materials and measured the enzymes. YS did the TEM sections and observed them. GW discussed the results and revised the manuscript. All authors read and approved the final manuscript.

\section{Funding}

This work was supported by National Natural Science Foundation of China (41876160, 41876163), National key R\&D program of China

(2016YFC1400602-03), and Key R\&D program of Yantai City (2018SFBF069).

These funding bodies had no role in study design, data collection, analysis, in writing the manuscript or the decision to submit the work for publication.

\section{Availability of data and materials}

All of the datasets supporting the results of this article are included within the article and its additional files. The raw reads of transcriptome in this study can be accessed with the link below: http://db.cngb.org/cnsa/project/ CNP0000880/reviewlink.

\section{Ethics approval and consent to participate}

Not applicable.

\section{Consent for publication}

Not applicable.

\section{Competing interests}

All the authors declare that they have no competing interests.

Received: 21 February 2020 Accepted: 30 August 2020

Published online: 15 September 2020

\section{References}

1. Gao K, McKinley KR. Use of macroalgae for marine biomass production and $\mathrm{CO}_{2}$ remediation: a review. J Appl Phycol. 1994;6:45-60.

2. Muraoka D. Seaweed resources as a source of carbon fixation. Bull Fish Res Agen Supplement. 2004;1:59-63.

3. Chung IK, Beardall J, Mehta S, Sahoo D, Stojkovic S. Using marine macroalgae for carbon sequestration: a critical appraisal. J Appl Phycol. 2011;23:877-86.

4. Millero FJ. Chemical oceanography [M]. 4th ed. Boca Raton: CRC Press; 2013. p. 259-333.

5. Li XH, Xu JT, He PM. Comparative research on inorganic carbon acquisition by the macroalgae Ulva prolifera (Chlorophyta) and Pyropia yezoensis (Rhodophyta). J Appl Phycol. 2016;28:491-7.

6. Kevekordes K, Holland D, Haubner N, Jenkins S, Koss R, Roberts S, Raven JA, Scrimgeour CM, et al. Inorganic carbon acquisition by eight species of Caulerpa (Caulerpaceae, Chlorophyta). Phycologia. 2006;45(4):442-9.

7. Chen BB, Lin LD, Ma ZL, Zhang TT, Chen WZ, Zou DH. Carbon and nitrogen accumulation and interspecific competition in two algae species, Pyropia haitanensis and Ulva lactuca, under ocean acidification conditions. Aquac Int. 2019:27:721-33.

8. Wu HX, Zou DH, Gao KS. Impacts of increased atmospheric $\mathrm{CO}_{2}$ concentration on photosynthesis and growth of micro-and macro-algae. Sci China Ser C Life Sci. 2008:51:1144-50.

9. Hepburn CD, Pritchard DW, Cornwall CE, McLeod RJ, Beardall J, Raven JA, Hurd CL. Diversity of carbon use strategies in a kelp forest community: implications for a high $\mathrm{CO}_{2}$ ocean. Glob Chang Biol. 2011;17:2488-97.

10. Kanai R, Edwards EG. The biochemistry of C4 photosynthesis. C4 plant biology. 1999;121:49-87.

11. Huertas E, Colman B, Espie GS. Mitochondrial-driven bicarbonate transport supports photosynthesis in a marine microalga. Plant Physiol. 2002;130:284-91.

12. Klodmann J, Sunderhaus S, Nimtz M, Jansch L, Braun HP. Internal architecture of mitochondrial complex I from Arabidopsis thaliana. Plant Cell. 2010;22(3):797-810.

13. Wang $X L$, He LW, Ma YC, Huan L, Wang YQ, et al. Economically important red algae resources along the chines coast: history, status, and prospects for their utilization. Algal Res. 2020. https://doi.org/10.1016/j.algal.2020.101817.

14. Kitade Y, Taguchi G, Shin JA, Saga N. Porphyra monospore system (Bangiales, Rhodophyta): a model for the developmental biology of marine plants. Phycol Res. 1998:46:17-20. 
15. Saga N, Kitade Y. Porphyra: a model plant in marine sciences, Fish. Sci. 2002; 68(Suppl):1075-8.

16. Bao ML, Wang JH, Xu TP, Wu HL, Li XS, Xu JT. Rising CO2 levels alter the responses of the red macroalga Pyropia yezoensis under light stress. Aquaculture. 2019;501:325-30.

17. Gao K, Aruga Y, Asada K, Ishihara T, Akano T, Kiyohara M. Enhanced growth of the red alga Porphyra yezoensis Ueda in high CO2concentrations. J Appl Phycol. 1991;3:355-62.

18. Yue GF, and Zhou BC. Inorganic carbonate utilization by Porphyra yezoensis ueda oceanologia et limnologia sinica. 2000; 31(3):246-251 (English Abstract)

19. Luo QJ, Pei LQ, Pan SY, Wang Y, Fei ZQ. Utilization of inorganic carbon in free-living conchocelis of Porphyra haitanensis. J Fish China. 2002;26(5):47780 (Chinese with English abstract).

20. Yang H, Mao YX, Kong FN, Yang GP, Wang L. Profiling of the transcriptome of Porphyra yezoensis with Solexa sequencing technology. Chin Sci Bull. 2011:56(20):2119-30.

21. Fan XL, Fang YJ, Hu SN, Wang GC. Generation and analysis of 5318 expressed sequence tags from the filamentous sporophyte of Porphyra haitanensis (Rhodophyta). J Phycol. 2007;43:1287-94.

22. Xie CT, Li B, Xu Y, Ji DH, Chen CS. Characterization of the global transcriptome for Pyropia haitanensis (Bangiales, Rhodophyta) and development of cSSR markers. BMC Genomics. 2013;14:107 http://www. biomedcentral.com/1471-2164/14/107

23. Yang H, Mao YX, Kong FN, Yang GP, Ma F, Wang L. Profiling of the transcriptome of Porphyra yezoensis with Solexa sequencing technology. Chin Sci Bull. 2011;56(20):2119-30.

24. Wang $W$, Teng F, Lin Y, Ji D, Xu Y, Chen C, et al. Transcriptomic study to understand thermal adaptation in a high temperature-tolerant strain of Pyropia haitanensis. PLoS One. 2018;13(4):e0195842. https://doi.org/10.1371/ journal.pone.0195842.

25. Nakamura Y, Sasaki N, Kobayshi M, Ojima N, et al. The first symbiont-free genome sequence of marine red alga, Susabi-nori (Pyropia yezoensis). PLoS One. 8(3):e57122.

26. Krall JP, Edwards GE. Relationship between photosystem II activity and $\mathrm{CO}_{2}$ fixation in leaves. Physiol Plant. 1992;86:180-7.

27. Genty B, Harbinson J, Briantais JM, Baker NR. The relationship between photochemical quenching of chlorophyll fluorescence and the rate of photosystem II photochemistry in leaves. Photosynth Res. 1990;25:249-57.

28. Huan L, Wang C, He LW, Lu XP, Wang XL, Liu XH, Wang GC. Preliminary comparison of atmospheric $\mathrm{CO}_{2}$ enhancement to photosynthesis of Pyropia yezoensis (Bangiales, Rhodophyta) leafy thalli and filamentous thalli. Phycol Res. 2018;66:117-26.

29. Wang $Y Y$, Wang $W L, X u Y$, Ji DH, Chen CS. Physiological differences in photosynthetic inorganic carbon utilization between gametophytes and sporophytes of the economically important red algae Pyropia haitanensis. Algal Res. 2019;39:101436. https://doi.org/10.1016/j.algal.2019.101436.

30. Blinks LR. The effect of $\mathrm{pH}$ upon the photosynthesis of littoral marine algae. Protoplasma. 1963:57:126-36.

31. He PM, Wu WN, Zhao JH, Chen GY, Zhang DB. Studies on ultrastructure of pyrenoid from several algae. Acta Hydrobioligica Sinica. 2002;26(4):327-34 (Chinese with English abstract).

32. Shen SD, Dai JX, Zhou LY. Ultrastructure of vegetative and reproductive conchocelis of Porphyra yezoensis. Mar Sci Bull. 2000;19(3):38-44 (Chinese with English abstract).

33. Mei JX, Fei XG. The ultrastructure of separated and cultured cell of Porphyra yezoensis. 2001. Chin J Oceanol Limnol. 2001;19(1):35-9 (Chinese with English abstract)

34. Bre'he'lin C, Kessler F, Wijk KJV. Plastoglobules: versatile lipoprotein particles in plastids. Trends Plant Sci. 2007;12(6):260-6.

35. Rehman RU, Zia M, Abbasi HB, Lu G, Chaudhary MF. Ascorbic acid and salicylic acid mitigate $\mathrm{NaCl}$ stress in Caralluma tuberculata Calli. Appl Biochem Biotechnol. 2014;173:968-79.

36. Wu XW, Lu XP, Riaz M, Yan L, Jiang CC. Boron toxicity induced specific changes of cell ultrastructure and architecture of components in leaf center and tip of trifoliate orange [Poncirus trifoliata (L.) Raf.]. J Environ Manag. 2019;246:426-33.

37. Xu K, Chen HZ, Wang WL, Xu Y, Ji DH, Chen CS, Xie CT. Responses of photosynthesis and $\mathrm{CO}_{2}$ concentrating mechanisms of marine crop Pyropia haitanensis thalli to large $\mathrm{pH}$ variations at different time scales. Algal Res. 2017;28:200-10
38. Wang SG, Yang Y, Zhou XQ, Song DD, Xue S, Luo QJ. Utilization of inorganic carbon in Pyropia haitanensis (rhodophyta) under heat stress. Oceanologia et Limnologia Sinica. 2013;44(5):1378-85 (Chinese with English abstract).

39. Zou DH, Gao KS. Photosynthetic bicarbonate utilization in Porphyra haitanensis (Bangiales, Rhodophyta). Chin Sci Bull. 2002;47:1629-33.

40. Poschenrieder C, Fernández JA, Rubio L, Pérez L, et al. Transport and use of bicarbonate in plants: current knowledge and challenges ahead. Int J Mol Sci. 2018;19:1352. https://doi.org/10.3390/ijms19051352.

41. Fernández PA, Hurd CL, Roleda MY. Bicarbonate uptake via an anion exchange protein is the main mechanism of inorganic carbon acquisition by the giant kelp Macrocystis pyrifera (Laminariales, Phaeophyceae) under variable pH. J Phycol. 2014;50. https://doi.org/10.1111/jpy.12247.

42. Wang $Y$, Spalding MJ. Acclimation to very low CO2: contribution of limiting CO2 inducible proteins, LClb and LCIA, to inorganic carbon uptake in Chlamydomonas reinhardtii. Plant Physiol. 2014;166:2040-50.

43. Wei L, Hajjami ME, Shen C, You WX, Lu YD, Li J, et al. Transcriptomic and proteomic responses to very low $\mathrm{CO}_{2}$ suggest multiple carbon concentrating mechanisms in Nannochloropsis oceanica. Biotechnol Biofuel. 2019;12:168. https://doi.org/10.1186/s13068-019-1506-8.

44. Nakajima K, Tanaka A, Matsuda Y. SLC4 family transporters in a marine diatom directly pump bicarbonate from seawater. Proc Natl Acad Sci U S A. 2013;110(5):1767-72.

45. Xu ZM, Yao NY, Li JZ. Studies on the activity of PEP carboxykinase in Laminaria japonica. Mar Sci. 1991;15(2):41-5 (Chinese with English abstract).

46. Shao ZR, Wang WL, Zhang PY, Yao JT, Wang FH, Duan DL. Genome-wide identification of genes involved in carbon fixation in Saccharina japonica and responses of putative C4-related genes to bicarbonate concentration and light intensity. Plant Physiol Biochem. 2019;137:75-83.

47. He LW, Zhang XJ, Wang GC. Expression analysis of phosphoenolpyruvate carboxykinase in Porphyra haitanensis (Rhodophyta) sporophytes and gametophytes. Phycol Res. 2013;61:172-9.

48. Kremer BP, Küppers U. Carboxylating enzymes and pathway of photosynthetic carbon assimilation in different marine algae-evidence for the C4-pathway? Planta. 1977;133:191-6.

49. Tsuji Y, Suzuki I, Shiraiwa Y. Photosynthetic carbon assimilation in the Coccolithophorid Emiliania huxleyi (Haptophyta): evidence for the predominant operation of the $C_{3}$ cycle and the contribution of $\beta$ -carboxylases to the active anaplerotic reaction. Plant Cell Physiol. 2009; 50(2):318-29.

50. Tsuji Y, Suzuki I, Shiraiwa Y. Enzymological evidence for the function of a plastid-located pyruvate carboxylase in the haptophyte alga Emiliania huxleyi: a novel pathway for the production of C4 compounds. Plant Cell Physiol. 2012;53(6):1043-52.

51. Nakazawa M, Minami T, Teramura K, Kumamoto S, et al. Molecular characterization of a bifunctional glyoxylate cycle enzyme malate synthase/ isocitrate lyase, in Euglena gracilis. Comp Biochem Physiol Part B. 2005;141: 445-52.

52. Nakazawa M, Nishimura M, Inoue K, Ueda M, Inui H, Nakano Y, Miyatake K. Characterization of a bifunctional glyoxylate cycle enzyme, malate synthase/ isocitrate lyase, of Euglena gracilis. J Eukaryot Microbiol. 2011;58(2):128-33.

53. Zhang BY, Yang F, Wang GC, Peng G. Cloning and quantitative analysis of the carbonic anhydrase gene from Porphyra yezoensis Ueda. J Phycol. 2010; 46:290-6.

54. Claros MG. MitoProt, a macintosh application for studying mitochondrial proteins. Comput Appl Biosci. 1995;11(4):441-7.

\section{Publisher's Note}

Springer Nature remains neutral with regard to jurisdictional claims in published maps and institutional affiliations. 